NBER WORKING PAPER SERIES

\author{
MEASURING THE WELFARE \\ EFFECT OF QUALITY CHANGE: \\ THEORY AND APPLICATION \\ TO JAPANESE AUTOS
}

Robert C. Feenstra

Working Paper No. 4401

\author{
NATIONAL BUREAU OF ECONOMIC RESEARCH \\ 1050 Massachusetts Avenue \\ Cambridge, MA 02138 \\ July 1993
}

The author thanks Erwin Diewert and Zvi Griliches for helpful discussions. Financial suppor from the Ford Foundation is gratefully acknowledged. This paper is part of NBER's research programs in International Trade and Investment and Productivity. Any opinions expressed are those of the author and not those of the National Bureau of Economic Research. 


\title{
MEASURING THE WELFARE \\ EFFECT OF QUALITY CHANGE: \\ THEORY AND APPLICATION \\ TO JAPANESE AUTOS
}

\begin{abstract}
The purpose of this paper is to identify conditions under which hedonic price indexes provide an exact measure of consumer welfare, so that the welfare effects of quality change can be inferred. Our results are quite positive in providing a rational for existing practices, though the conditions needed to justify these practices are somewhat restrictive. An application of our results is provided to the increase in characteristics of Japanese autos sold in the United States following the imposition of quotas in 1981. We argue that consumers did not value the additional characteristics at their former shadow-values, but rather, attached a lower value to the increase in characteristics. We compute the exact index that reflects this lower imputed value, and compare it to the conventional quality adjustment. The deadweight loss associated with the quality change is between one-quarter and one-third of the value of upgrading.
\end{abstract}

\section{Robert C. Feenstra}

Department of Economics

University of Califomia

Davis, CA 95616

(916) 752-7022

and NBER 


\section{INTRODUCTION}

In many situations, public policy affects the quality or characteristics of products. Examples include pollution abatement regulations in autos (Bresnahan and Yao. 1985) and other industries; health and safety requirements: and international trade policies such as quotas, as we shall examine. In these contexts, it is important to measure the impact of the quality change on social welfare. as part of a broader cost-benefit analysis.

One method that is often used to measure the quality change is hedonic regressions, and the associated hedonic price indexes.' There is some difficulty. however, in inferring welfare effects from these methods. While the model of Rosen (1974) is often used to justify the relation between market prices and the characteristics of goods, it is not obvious what this market relation implies about consumer's welfare from purchasing goods embodying the characteristics. Thus, Triplett (1987, 1990) refers to the existing practice of hedonic price indexes as an "approximation" to the true measure of consumer welfare. A similar view is expressed by Griliches (1990, p. 189):

What is being estimated [by the hedonic regression] is actually the locus of intersections of the demand curves of different consumers with varying tastes and the supply functions of different firms with possibly varying technologies of production. One is unlikely, therefore, to recover the underlying utility and cost functions from such data alone. except is very special circumstances.

The interpretation of hedonic methods is even more difficult in the (realistic) situation where there are only a discrete number of goods, so that consumers are not optimizing in a marginal fashion over their choice of characteristics. In that case, firms will be selecting the characteristics bundle of each good.

11 Recent applications to various durable goods are described in Gordon (1990). 
The purpose of this paper is to identify circumstances under which hedonic price indexes do provide an exact measure of consumer welfare. so that the welfare effects of quality change can be inferred. We shall deal with both the cases where consumers optimize over a continuum of goods, and where firms choose characteristics with only a discrete number of goods. While our results are quite positive in providing a rational for existing practices, the conditions needed to justify these practices are somewhat restrictive. In this sense. our results also indicate the need for further research to enlarge the applicable range of hedonic methods.

We begin in section 2 with the case where consumers can choose any characteristics subject to a hedonic budget constraint. We allow for changes in the hedonic budget constraint over time, and across different varieties of the good. Assuming that the expenditure function defined over services of the good permits an exact price index to be evaluated, then we show how to construct the exact index using observed data on prices, quantities and characteristics. This result is a natural analog to the usual construction of an exact price index over prices of goods, and justifies what Triplett (1990. p. 39) refers to as an "explicit quality adjustment" in the price index.

In section 3. we suppose that the characteristics of a discrete number of products are chosen by firms. Subject to the special form of the utility function we assume, firms will choose the socially optimal level of characteristics, as in Swan (1970). This will imply that the basic result concerning the construction of the exact hedonic price index still applies. Our results do not extend as stated to more general utility functions, however, such as those considered by Spence (1975).

An application of our results is provided in sections 4 , where we discuss the increase in characteristics of Japanese autos sold in the United States 
following the imposition of quotas in 1981. This quality-upgrading has been earlier measured by Feenstra (1988), using conventional hedonic techniques. From the results in this paper, it can be argued that consumers did not value the additional characteristics at their former shadow-values, but rather, attached a lower value to the increase in characteristics. We therefore compute the exact index that reflects this lower imputed value, and compare it to the conventional quality adjustment. We are also able to attribute a deadweight loss to the quality-upgrading that occurred, and this loss is between one-quarter and onethird of the value of the upgrading.

\section{CONSUMER CHOICE OF CHARACTERISTICS}

Suppose that the product in question can be fully described by $j=1 \ldots . J$ characteristics, and that $i=1, \ldots . N$ varieties of the product are available, where the characteristics vector of variety $i$ in year $t$ is denoted by $z_{i t} \in R^{J}$. We will assume that the preferences of all consumers over these varieties can be represented by the aggregate utility function:

$$
U\left[f_{1}\left(z_{1 t}\right) x_{1 t} \ldots, f_{N}\left(z_{N t}\right) x_{N t}\right]
$$

Where $f_{i}\left(z_{i t}\right)$ denotes the services received from one unit of consumption of variety $i$, and $x_{i t}$ denotes the quantity consumed of variety $i$, in year $t$.

Both the existence of an aggregate utility function, and its special functional form in (1). are extremely important to our analysis. A measure of aggregate utility is usually assumed when trying to justify an exact price index. since the index is designed to accurately reflect changes in overall consumer welfare. The existence of aggregate demand functions in a characteristics framework has been investigated by Anderson, de Palma and Thisse (1989, 1992). though these results do not immediately justify (1) for two reasons. First. 
these authors are primarily concerned with aggregate demand rather than utility. and the relation between these is not immediate. ${ }^{2}$ Second, the results of these authors are obtained by assuming that the characteristics vector of each variety is fixed. In contrast. we shall be letting the characteristics zit vary, and it is unclear whether their demand results can be extended to that case.

Concerning the functional form of (1). We are assuming that the services received from all consumption of variety $i$ are given by the weakly separable form $f_{i}\left(z_{i t}\right) x_{i t}$, rather than the more general form $\psi_{i}\left(z_{i} t, x_{i}\right)$. In other words. each unit consumed yields the same services of $f_{i}\left(z_{i t}\right)$. This is very similar to Fisher and Shell's (1972) notion of "repackaging." where the scalar quality of each good multiplies the quantity in the utility function. A good example is when the services received from a good depend on its durability. which multiplies the stock to obtain the service flow. In an intertemporal framework. Swan (1970) establishes the social optimality of the monopoly (or competitive) choice of durability. ${ }^{3}$ This result will carry over to the utility function (1). where we shall demonstrate the optimality of the monopolistically competitive choice of characteristics (see section 3 ). This key result certainly depends on the weak separability assumed: Spence (1975) considers more general utility functions like $\psi_{i}\left(z_{i}, x_{i}\right)$, and argues that the monopoly (or competitive) choice of quality are not optimal. In that case the results in this paper will not follow as stated, as discussed further in the concluding section. We suppose that the price of variety $i$ is given by a "hedonic function."

$$
\text { pit }=h_{i t}\left(z_{i t}\right) \text {. }
$$

2 Jorgenson (1990) describes an approach to integrating aggregate demand functions and social wellare in the absence of characteristics.

3 Abel (1983) investigates the general validity of Swan's result when marginal costs of the firm are not constant. 
where the consumers are allowed to choose the characteristics $z_{i t}$. Thus, we have in mind a situation where the characteristics of each variety can be specified by consumers prior to purchase, and the hedonic functions may change over time. Any product for which consumers can specify the characteristics would serve as an example. We assume that the utility function (1) is maximized over the choice of $x_{i t} \geq 0$ and $z_{i t}$. subject to the budget constraint:

$$
\sum_{i=1}^{N} h_{i t}\left(z_{i t}\right) x_{i t} \leq E_{t} .
$$

where $E_{t}$ is total expenditure on the good in year $t$. While the first-order conditions for this problem are readily computed. to characterize the secondorder conditions it will be useful to rewrite the maximization slightly.

Let $E_{i t}$ denote the expenditure on variety $i$ in year $t$, so that the quantity purchased must be $x_{i t}=E_{1 t} / p_{i t}=E_{i t} / h_{i t}\left(z_{i t}\right)$. Substituting this into (1), the optimization problem can be restated as:

$$
\max _{E_{i t} \geq 0 . z_{i t}} U\left[E_{1 t} f_{1}\left(z_{1 t}\right) / h_{1 t}\left(z_{1 t}\right) \ldots . E_{N t} f_{N}\left(z_{N t}\right) / h_{N t}\left(z_{N t}\right)\right]
$$

subject to.

$$
\sum_{t=1}^{N} E_{i t} \leq E_{t} .
$$

It is immediate that maximizing ( $4 a)$ implies maximizing $f_{i}\left(z_{i t}\right) / h_{i} t\left(z_{i} t\right)$. which is interpreted as the services provided per dollar of expenditure on variety $i$. The first-order condition for this sub-problem is:

$$
\frac{1}{f_{i}} \frac{\partial f_{i}\left(z_{i t}\right)}{\partial z_{i} t}=\frac{1}{h_{i} t} \frac{\partial h_{i t}\left(z_{i t}\right)}{\partial z_{i} t} .
$$

This condition states that there is equality between the relative marginal cost 
and marginal benefit of adding each characteristic: increasing a characteristic must lead to the same percentage increase in costs and benefits at the optimum. A sufficient condition for the point $z i t$ satisfying (5) to be a global maximum of $f_{i}\left(z_{i t}\right) / h_{i t}\left(z_{i t}\right)$ is that this ratio is quasi-concave in $z_{i t}$. which holds if and only if $\left[\ln f_{i}\left(z_{i t}\right)-\operatorname{lnh} h_{i t}\left(z_{i t}\right)\right]$ is quasi-concave. Thus, to ensure that this second-order condition is satisfied, we will make the stronger assumption: 4

\section{Assumption 1}

The function $\ln f_{i}\left(z_{i t}\right)$ is concave and $\ln h_{i t}\left(z_{i t}\right)$ is convex in $z_{i t}, i=1, \ldots, N$.

We will also want to add a second assumption, related to the existence of an exact price index: the results in this paper will then show how to measure the index. To this end, define $y_{i t} \equiv f_{i}\left(z_{i t}\right) x_{i t}$ as the total consumption services from variety $i$, and $q_{i t} \equiv p_{i t} / f_{i}\left(z_{i t}\right)$ as the price per unit of services. Note that these magnitudes are not be observed by the researcher, since $f_{i}\left(z_{i t}\right)$ is unknown. The utility function (1) is $U\left(y_{t}\right)$, which we assume is homothetic in $y_{t ;}$ by choice of units for utility. it is also taken to be homogeneous of degree one. Then the dual expenditure function $E\left(q_{t}, U_{t}\right)$ can be written as $E\left(q_{t}, U_{t}\right)=e\left(q_{t}\right) U_{t}$, where $e\left(q_{t}\right)$ is the unit-expenditure function. Diewert (1976) defines a price index to be exact if it equals the ratio $e\left(q_{t}\right) / e\left(q_{t-1}\right)$. which can be interpreted as the change in the cost of living between two periods. Our next assumption will be that such an exact price index exists. To state this formally, assume that the consumption vector $y_{\tau}$ maximizes utility for the services-prices $q_{\tau}$, and the budget constraint $q_{\tau}^{\dot{y}} y_{\tau} \leq E_{\tau}$, for $\tau=t-1, t$, and let $s_{i \tau}=p_{i} x_{i \tau} / E_{\tau}$ denote the budget share on variety $i$.

4 The other second-order condition for problem (4) is that $U$ is quasi-concave. 


\section{Assumption 2}

Letting $Q_{t} \equiv\left(a_{1 t} / a_{1} t-1, \ldots, q_{N t} / q_{N t-1}\right)$ denote the vector of service-price ratios, there exists a price index $P\left(Q_{t}, s_{t-1}, s_{t}\right)$ such that $P\left(Q_{t}, s_{t-1}, s_{t}\right)=e\left(q_{t}\right) / e\left(q_{t-1}\right)$. with $\partial P / \partial O_{t} \geq 0$.

Diewert (1976) demonstrates the existence of an exact index for a wide class of unit-expenditures functions called "quadratic means of order r." which include the quadratic. translog, constant elasticity of substitution (CES), and a number of other common functional forms. The formula for the exact price index depends on the price ratios and expenditure shares $i$ each period. and satisfies the condition that an increase in the price ratio for any good increases the index, as stated in Assumption 2.

Since the service prices $q_{t}$ are not observed by the researcher, the index number $P\left(O_{t}, s_{t-1}, s_{t}\right)$ cannot be directly measured. We shall assume, however, that information about the consumers' budget constraint (2) is available. While the entire hedonic function $h_{i t}\left(z_{i}\right)$ may not be observed. we can expect that these functions are known at least in a neighborhood of the characteristics $z_{i t}$ chosen by the consumers, satisfying (5). We state this requirement as:

\section{Assumption 3}

The hedonic prices $\beta_{i t} \equiv \partial \ln h_{i t}\left(z_{i t}\right) / \partial z_{i t}$ are observed, where $z_{i t}$ satisfies (5).

Using these "hedonic prices" along with condition (5), and the concavity of $\ln f_{i}\left(z_{i t}\right)$ from Assumption 1, we obtain the bounds:

$$
\beta_{i t}\left(z_{i t}-z_{i t-1}\right) \leq \ln f_{i}\left(z_{i t}\right)-\ln f_{i}\left(z_{i t}-1\right) \leq \beta_{i t-1}^{\prime}\left(z_{i t}-z_{i t-1}\right) .
$$

Inverting this expression, taking the exponent, and multiplying by the price ratio (pit/pit-1) we obtain: 


$$
\frac{P_{i t}}{P_{i t}-1} \exp \left[-\beta_{i t-1}^{\prime}\left(z_{i t}-z_{i t-1}\right)\right] \leq Q_{i t} \leq \frac{P_{i t}}{P_{i t}-1} \exp \left[-B_{i t}^{i}\left(z_{i t}-z_{i t-1}\right)\right]
$$

Where we haved used the service-prices $q_{i t} \equiv p_{i t} / f_{i}\left(z_{i t}\right)$, and the price ratios $Q_{i t}$ defined in Assumption 2. Then using $\partial P / \partial Q_{t} \geq 0$ in Assumption 2. we obtain:

\section{Proposition 1}

Under Assumptions 1-3, the exact index $P\left(O_{t}, s_{t-1}, s_{t}\right)$ satisfies:

$$
P\left(t-1 O_{t}, s_{t-1}, s_{t}\right) \leq P\left(O_{t}, s_{t-1}, s_{t}\right) \leq P\left(t \hat{Q}_{t}, s_{t-1}, s_{t}\right),
$$

where $\tau \hat{Q}_{t} \equiv\left(p_{i t} / p_{i t-1}\right) \exp \left[-\beta_{i \tau}\left(z_{i t}-z_{i t-1}\right)\right]$, for $\tau=t-1, t$.

This result provides bounds on the exact index $P\left(Q_{t}, s_{t-1}, s_{t}\right)$, where these bounds can be measured with the observed prices, market shares, and the hedonic prices $\beta_{i t}$. Notice that the service-price ratios ${ }_{\tau} \hat{\partial}_{t}$ used in the bounds are obtained by multiplying ( $\left.p_{i t} / p_{i t-1}\right)$ by the term exp[- $\left.\beta_{i \tau}^{i}\left(z_{i t}-z_{i t-1}\right)\right]$, which corresponds to the "explicit quality adjustment" described by Triplett (1990, p. 39). This adjustment is made using the period $t-1$ hedonic prices $B_{i t-1}$ in the lower-bound, and period $t$ values $\beta_{1 t}$ in the upper-bound. In practice, if these hedonic prices are constant (or changing insignificantly) over time, then the lower and upper-bounds in part (a) are identical, and a unique measure of the price index is obtained.

An extension of this result can be obtained under the assumption the $\ln f_{i}\left(z_{i t}\right)$ is quadratic, so that the inequalities in $(6)$ can be stated as:

$$
\ln f_{i}\left(z_{i t}\right)-\ln f_{i}\left(z_{i t-1}\right)=\frac{1}{2}\left(\beta_{i t-1}+\beta_{i t}\right)^{\prime}\left(z_{i t}-z_{i t-1}\right)
$$

due to the quadratic approximation lemma (Diewert, 1976). It follows that 
$O_{t}=\left[\left(t-1 \hat{Q}_{t}\right)\left(t \hat{Q}_{t}\right)\right]^{0.5}$. If the exact price index $P$ can be written as a weighted geometric mean of the price ratios $Q_{i t} .^{5}$ then this index can also be measured as the geometric mean of the bounds in Proposition 1.

\section{FIRM CHOICE OF CHARACTERISTICS}

We shall now suppose that the characteristics $z_{i t}$ of each variety are treated as exogenous by consumers. Their problem is to simply choose the optimal quantity $x_{i t}$ of each variety, or equivalently. the demand for services $y_{i t} \equiv f_{i}\left(z_{i t}\right) x_{i t}$. Let $y_{t}=D\left(q_{t}, E_{t}\right)$ denote the demand for the services of each variety. Firm's simultaneously choose the characteristics and price of each variety to maximize profits, under monopolistic competition. Let $g_{i t}\left(z_{i t}\right)$ denote the cost of producing one unit of variety $i$ in year $t$. which is assumed to be independent of output. We suppose that each variety is produced by only one firm, though each firm may produce multiple varieties.

Assume that firms treat the prices and characteristics chosen by other firms as fixed. If the firm is producing varieties $1, \ldots, M$, then the profitmaximization problem is stated as:

$$
\max _{p_{i t}>0, z_{i t}} \sum_{i=1}^{M}\left[p_{i t}-g_{i t}\left(z_{i t}\right)\right] x_{i t} \equiv \max _{q_{i t}>0, z_{i t}} \sum_{i=1}^{M}\left[q_{i t}-\frac{g_{i t}\left(z_{i t}\right)}{f_{i}\left(z_{i t}\right)}\right] D_{i}\left(q_{t}, E_{t}\right),
$$

where $x_{i t}$ on the left of $(g)$ depends on the maximizing variables $p_{i t}$ and $z_{i t}$. since $x_{i t} \equiv D_{i}\left(q_{t}, E_{t}\right) / f_{i}\left(z_{i t}\right)$ and $q_{i t} \equiv p_{i t} / f_{i}\left(z_{i t}\right)$. These definitions are used to obtain the expression on the right, where firms are then maximizing over the

5 A weighted geometric formula of the type $P=\prod_{i}\left(Q_{i t} / Q_{i t-1}\right)^{w_{i t}}$ applies for the index number when the unit-expenditure function is translog. CES, and as an

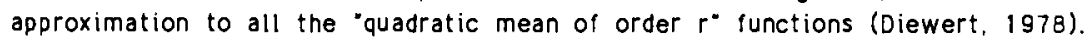


choice of characteristics and service-prices $q_{i t}{ }^{6}$ it is immediate that to maximize the right of ( 9 ). firms must minimize $g_{i t}\left(z_{i t}\right) / f_{i}\left(z_{i t}\right)$, which is interpreted as the cost of supplying one unit of consumption services. The first-order condition for this sub-problem is,

$$
\frac{1}{f_{i}} \frac{\partial f_{i}\left(z_{i t}\right)}{\partial z_{i t}}=\frac{1}{g_{i t}} \frac{\partial g_{i t}\left(z_{i t}\right)}{\partial z_{i t}} .
$$

which is analogous to (5). A sufficient condition for the characteristics satisfying (10) to globally maximize profits is that:?

\section{Assumption 1:}

The function $\ln f_{i}\left(z_{i t}\right)$ is concave and $\ln g_{i t}\left(z_{i t}\right)$ is convex in $z_{i t}, i=1 \ldots . . N$.

Thus, with firms choosing characteristics to maximize profits, we obtain an equality between the marginal benefit and marginal cost, as stated in (10). As noted earlier, this result depends on the special form of the utility function in (1). We will suppose that the marginal costs are known in a neighborhood of the equilibrium position:

\section{Assumption $3^{\circ}$}

The relative marginal cost of characteristics $\beta_{i t} \equiv \partial \operatorname{lng} g_{i t}\left(z_{i t}\right) / \partial z_{i t}$ are observed, where $z_{i t}$ satisfies $(10)$,

It is then immediate that Proposition 1 still holds:

6 This change in maximizing variables depends on having firms choose prices and characteristics simultaneously.

7 The other condition needed to ensure that profits are globally maximized in (13) is that profits are quasi-concave in prices $q t$, for fixed characteristics. 


\section{Corollary 1}

Under Assumption 1', 2 and 3'. Proposition 1 holds as stated.

This extension of Proposition 1 means that it can be applied even when there is a discrete number of products. whose basic characteristics cannot be chosen by consumers. This describes the purchases of automobiles, for example. and in the next section we shall apply the results of Proposition 1 to Japanese autos imported to the U.S. These imports have been subject to a "voluntary" export restraint (VER) since 1981, and experienced a dramatic increase in their characteristics under this trade restriction. In the remainder of this section We reexamine the firm's profit-maximization problem under the VER.

The Ministry of International Trade and Industry (MITI) in Japan specifies the maximum number of autos exported to the U.S. for each firm, on an annual basis. Denoting this limit by $\bar{x}_{t}$, a firm producing the varieties $i=1, \ldots, M$ solves:

$$
\max _{a_{i t}>0, z_{i t}} \sum_{i=1}^{M}\left[q_{i t}-\frac{g_{i t}\left(z_{i t}\right)}{f_{i}\left(z_{i t}\right)}\right] D_{i}\left(q_{t}, E_{t}\right) \text { st. } \sum_{i=1}^{M} D_{i}\left(q_{t}, E_{t}\right) / f_{i}\left(z_{i t}\right) \leq \overline{x_{t}} \text {. }
$$

where $x_{i t} \equiv D_{i}\left(q_{t}, E_{t}\right) / f_{i}\left(z_{i t}\right)$ denotes the exports of model $i$ in year $t$.

Letting $\lambda_{t}$ denote the Lagrange multiplier on the constraint in (12), the first-order condition with respect to the characteristics is.

$$
\frac{1}{f_{i}} \frac{\partial f_{i}\left(z_{i t}\right)}{\partial z_{i t}}=\left[\frac{\partial g_{i t}\left(z_{i t}\right) / \partial z_{i t}}{\lambda_{t}+g_{i t}\left(z_{i t}\right)}\right] \equiv \beta_{i t} .
$$

Thus, in contrast to $(10)$, we do not obtain an equality between the firm's relative marginal cost and consumer's marginal benefit of characteristics. This equality is broken by the binding VER constraint, and higher values of $\lambda_{t}$ will be 
associated with an increase in characteristics, when weighted by the initial marginal benefits $\partial \ln f_{i}\left(z_{i t}\right) / \partial z_{i t}$ :

$$
\left.\frac{\partial \ln f_{i}\left(z_{i t}\right)^{\prime}}{\partial z_{i t}} \frac{d z_{i t}}{d \lambda_{t}}\right|_{\lambda_{t}=0}=\frac{\partial \ln f_{i}\left(z_{i t}\right)^{\prime}}{\partial z_{i t}}\left[\frac{\partial^{2} \ln g_{i t}\left(z_{i t}\right)}{\partial z_{i t}}-\frac{\partial^{2} \ln f_{i}\left(z_{i t}\right)}{\partial z_{i t}}\right] \frac{\partial \ln f_{i}\left(z_{i t}\right)}{\partial z_{i t}} .
$$

which is nonnegative from Assumption 1:. Thus, as the VER becomes more binding, firms choose to upgrade the characteristics.

To interpret condition (13), note that if consumer's faced the budget constraint $h_{i t}\left(z_{i t}\right) \equiv \lambda_{t}+g_{i t}\left(z_{i t}\right)$, and maximized over the choice of characteristics. then condition (13) would follow directly from (5). 8 That is, the increase the price of all varieties by the dollar amount $\lambda_{t}$ would lower the marginal cost of any characteristic relative to the total price of the product (which is higher). Then at the optimum, consumers would also increase their purchases of characteristics so as to lower the marginal utility received, relative to total utility. Thus, quality upgrading is obtained, regardless of whether consumers or firms choose the characteristics.

Returning to the firm's problem, the other first-order condition for (12) is obtained by maximizing over $q_{i t}$ :

$$
\sum_{j=1}^{M}\left[p_{j t}-g_{j t}\left(z_{j t}\right)-\lambda_{t}\right]\left[\frac{1}{f_{j}\left(z_{j}\right)} \frac{\partial D_{j}}{\partial q_{i t}}\right]=-D_{i}\left(q_{t}, E_{t}\right) .
$$

From this condition. the equilibrium prices can be solved as: 9

8 As we note below. the price paid by consumers actually exceeds $\lambda_{t}+g_{i t}\left(z_{i t}\right)$. but we use this example to interpret the results.

9 To obtain (15) we make use of the symmetry relation $\partial D_{i} / \partial q_{j}=\partial D_{j} / \partial q_{i}$, which holds if the number of varieties is large, so that income effects can be ignored. 


$$
\left(1-\mu_{i t}\right) p_{i t}=\lambda_{t}+g_{i t}(z i t)
$$

where: $\mu_{i t} \equiv \sum_{j=1}^{M} B_{i j}$ and $B$ denotes the inverse of the matrix of elasticities $A$. with elements $A_{i j}=-\left(\frac{\partial D_{i t}}{\partial q_{j t}} \frac{q_{j t}}{D_{i t}}\right)=-\left(\frac{\partial x_{i t}}{\partial p_{j t}} \frac{p_{j t}}{x_{i t}}\right)$.

The expression $\left(1-\mu_{i t}\right)$ pit on the left of (15) should be interpreted as a generalized marginal revenue, which takes into account the effect of one extra unit of variety $i$ on all the prices $p_{j t}, j=1, \ldots, M$, and thus on total revenue of the firm. From (15), marginal revenue of each variety exceeds marginal cost by the multiplier $\lambda_{t}$. In our estimation we also assume that this multiplier is the same across exporting firms.

\section{QUALITY-UPGRADING IN JAPANESE AUTOS}

Feenstra (1988) estimates of the following regression over 1979-85 for the base version of all Japanese autos imported to the U.S.:

$$
p_{i t}=s_{t}+\exp \left(\alpha_{t}+\gamma^{\prime} z_{i t}\right)+\varepsilon_{i t} .
$$

where the characteristics $z_{i t}$ include weight, width, height, horsepower. type of transmission, and whether the car has power steering or air conditioning as standard equipment. The coefficients st measure the dollar increase in the price of each auto due to the VER constraint. while coefficients $\alpha$ measure the annual change in prices that would have occurred even in the absence of the VER. 10

To make the connection between the hedonic regression (16) and the pricing relation (15), define $\rho_{i t} \equiv \mu_{i t} /\left(1-\mu_{i t}\right)$. so that $\left(1+p_{i t}\right)=\left(1-\mu_{i t}\right)^{-1}$ is the markup

10 The estimated regression is reported in the Appendix. 
over marginal costs in (15). We will treat $\rho_{i t}$ as a random variable across models, with mean value $\bar{\rho}_{t}$. Then $(15)$ and $(16)$ are equivalent with the definitions:

$$
\begin{aligned}
& s_{t} \equiv\left(1+\overline{\rho_{t}}\right) \lambda_{t} . \\
& \exp \left(\alpha_{t}+\gamma^{\prime} z_{i t}\right) \equiv\left(1+\overline{\rho_{t}}\right) g_{i t}\left(z_{i t}\right), \\
& \varepsilon_{i t} \equiv\left(\rho_{i t}-\overline{\rho_{t}}\right)\left[\lambda_{t}+g_{i t}\left(z_{i t}\right)\right] .
\end{aligned}
$$

Thus, $s_{t}$ is an inflated version of the multiplier $\lambda_{t}$, and should be interpreted as the quota-premium earned on each unit sold. Similarly, exp $\left(\alpha_{t}+\gamma^{\prime} z_{i t}\right)$ is an inflated version of marginal costs, which incorporates the average markup $\overrightarrow{p_{t}}$. Provided that $\mathrm{p}_{\mathrm{t}}$ is uncorrelated with the characteristics $z_{i t}$, then the error term Eit will also be uncorrelated with the characteristics, and we can expect (16) to provide unbiased estimates of the marginal cost parameters $\gamma .11$

In Table 1, we report the unit-price and price index for the sample of Japanese imported autos, and also the unit-quality and quality index, which are slightly revised from Feenstra (1988). 12 Quality for each model is constructed as the exponential of the linear combination of physical characteristics, using the coefficients $\hat{z}$. These are averaged using the annual sales to obtain unitquality, and aggregated using the Fisher-Ideal formula to obtain the quality index; the same averaging and Fisher-Ideal formula are used to obtain the unitprice and price index.

It is apparent from a comparison of the price and quality indexes in Table

11 Estimating (16) will lead to an upward bias in the marginal cost parameters if the markups are correlated with the characteristics. In the Appendix we check for this correlation in the 1985 year, using estimates of the markups $\hat{\mu}_{i 85}$ from Feenstra and Levinsohn (1991). There is little evidence of bias in the coefficients $\hat{\gamma}$ due to incorporating the markups into the error.

12 The principal changes are that the 1985 sales data were revised, and there is no imputation for new car models before they actually appear. 
1 that increases in the physical characteristics of Japanese imported autos account for fully one-half of the increase in price over 1980-85: the price index increases $49 \%$ over this period, while the quality index increases by $26 \%$. The ratio of these two indexes is also shown in the middle of Table 1 , and this ratio rises by 18\% over 1980-85. While about one-half of the rise in prices is accounted for by the quality upgrading, it would be incorrect to draw any inference about the welfare of U.S. consumers from this comparison. The reason is that the quality index in Table 1 is constructed using constant coefficients $\hat{\gamma}$ to evaluate the characteristics, whereas the correct welfare weights $\beta_{\text {it }}$ in (13) are not constant.

Using the definitions in (17), the welfare weights $B_{i t}$ from (13) can be evaluated as:

$$
\beta_{i t}=\gamma\left[\frac{\exp \left(\alpha_{t}+\gamma^{\prime} z_{i t}\right)}{s_{t}+\exp \left(\alpha_{t}+\gamma^{\prime} z_{i t}\right)}\right] .
$$

Thus, the consumer valuation of the additional characteristics is less than the coefficients $\gamma$, by an amount that falls as the quota premium st increases. The estimates of the quota premium from Feenstra (1988) range from $\$ 434$ in 1981 to a high of $\$ 1.096$ in 1984 , and the corresponding average value of the fraction on the right of $(18)$ is 0.93 and 0.86 in these years. Thus, the correct valuation of the additional characteristics fluctuates around $90 \%$ of the coefficients $\delta$. Using (18) to obtain $\beta_{i t}$. Proposition 1 can be applied as stated to measure the exact price index for Japanese imported autos. The lower-bound and upperbounds for the exact index are shown in Table 1. Comparing these to the price/quality ratio, we see that the exact index rises more over the period of the VER, due to the diminishing consumer valuation of the added characteristics. It is tempting to interpret the difference between the exact index and the 
price/quality ratio as a measure of the deadweight loss of the upgrading caused by the VER, since consumers value the additional characteristics by less than their budget cost from the hedonic regression. To make the measure of loss more precise, however, we need to compare the VER to some other trade instrument that would not cause the upgrading.

Applying an ad valorem tariff will not lead to any change in the quality choice by firms. since a proportional increase in costs $g_{i t}\left(z_{i t}\right)$ will not affect the equality of the relative marginal cost and marginal benefit of each characteristic in (10). If a tariff of $\tau_{t}$ were applied instead of the VER, we will suppose that prices would equal $\left(1+\tau_{t}\right) \tilde{p}_{i t}$. Where:

$$
\tilde{p}_{i t}=\exp \left(\alpha_{t}+\gamma^{\prime} z_{i 0}\right)
$$

is a measure of the free-trade prices. In comparison with (16), we are setting the quota-premium st equal to zero in (19), and keeping the characteristics of each model constant at some base level $z_{10}$ (which will be their 1980 level). For the purpose of comparing the tariff with the VER, we also ignore the error term in (16). by supposing that the markup $\rho_{i t}$ is constant and equal across all models.

The losses imposed by the VER and tariff will depend on the magnitude of each. Rodriguez (1979), Krishna (1987) and Anderson (1988) argue that if the tariff and quota are set to lead to the same physical quantity of imports, then the quota will have a lower deadweight loss, precisely because the upgrading allows for a higher level of service imports. On the other hand, if the tariff and quota are designed to lead to the same aggregate price, then it will be demonstrated below that the deadweight loss of the quota exceeds that of the tariff. For the purpose of measuring any additional loss due to the upgrading. this latter comparison seems most relevant. Thus, letting $\left(1+\tau_{t}\right) \bar{q}_{i t} \equiv$ 
$\left(1 \cdot z_{t}\right) \tilde{p}_{i t} / f_{i}\left(z_{i 0}\right)$ denote the service prices under the tariff, we will suppose that the tariff $\tau_{t}$ is chosen to satisfy:

$$
e\left(q_{t}\right)=e\left[\left(1+\tau_{t}\right) \tilde{q}_{t}\right]=\left(1+\tau_{t}\right) e\left(\tilde{q}_{t}\right)
$$

where $q_{i t} \equiv p_{i t} / f_{i}\left(z_{i t}\right)$ are the service prices under the VER, and the final equality in (20) follows since $e(q)$ is homogeneous of degree one.

The conventional definitions of the deadweight loss under the tariff and quota are the difference between the total expenditure with and without each policy, and the revenue or rents generated by it, where all are evaluated at a constant level of utility $U_{t}$ :

$$
\begin{aligned}
& L_{s} \equiv e\left(q_{t}\right) U_{t}-e\left(\tilde{q}_{t}\right) U_{t}-\sum_{i=1}^{N} s_{t} x_{i t} . \\
& L_{\tau} \equiv e\left[\left(1+\tau_{t}\right) \tilde{q}_{t}\right] U_{t}-e\left(\tilde{q}_{t}\right) U_{t}-\tau_{t} e\left(\tilde{q}_{t}\right) U_{t} .
\end{aligned}
$$

The final term in (21b) is the quota rents generated by the VER: since these accrue to Japanese firms, they must be added onto any measure of the social cost of the quota restriction. The additional loss of the VER due to the upgrading can be obtained as the difference between (21a) and (21b):

$$
\left(L_{s}-L_{\tau}\right)=U_{t} e\left(\tilde{q}_{t}\right) \tau_{t}-s_{t} \sum_{i=1}^{N} x_{i}=\sum_{i=1}^{N}\left(p_{i t}-s_{t}\right) x_{i t}-U_{t} e\left(\tilde{q}_{t}\right) .
$$

The first equality of (22) follows directly from (20) and (21). The second equality is obtained by noting that total expenditure $E_{t}$ is equal for the tariff and quota satisfying (20), so that $\sum_{i} p_{i t} x_{i t}=U_{t}\left(1+\tau_{t}\right) e\left(\tilde{q}_{t}\right)$.

The next result shows establishes that this additional loss is positive, and can be measured with observed prices and quantities: 
Proposition 2

The deadweight loss of the quota relative to the price-equivalent tariff is:

$$
\frac{\left(L_{s}-L_{\tau}\right)}{E_{t}}=\exp \left(\alpha_{t}-\alpha_{0}\right)\left[P_{a}^{-1}-P^{-1}\right]
$$

where $P_{a}$ is a quality-adjusted $P$ aasche index defined as:

$$
P_{a}=\left[\sum_{i=1}^{N} p_{i t} x_{i t}\right],\left[\sum_{i=1}^{N} p_{i 0} x_{i t} \exp \left[\gamma^{\prime}\left(z_{i t}-z_{i 0}\right)\right]\right] .
$$

and $P$ is an exact price index between periods 0 and $t$.

To prove this result, we use (19) to evaluate the free-trade prices $\tilde{p}_{i o}$ and $\tilde{q}_{i o}$ in the base period 1980, and (16) to evaluate the actual prices.13 Then $\left(p_{i t}-s_{t}\right)$ is related to the prices 1980 prices $p_{i o}$ by $p_{i t}-s_{t}=\exp \left(\alpha_{t}+\gamma^{\prime} z_{i t}\right)=$ $p_{i 0} \exp \left(\alpha_{t}-\alpha_{0}\right) \exp \left[\gamma^{\prime}\left(z_{i t}-z_{10}\right)\right]$. In addition, the free-trade service prices $\tilde{q}_{i t} \equiv \exp \left(\alpha_{t}+\gamma z_{10}\right) / f_{i}\left(z_{10}\right)$ in $(22)$ are related to the 1980 service prices $q_{10}$ by $\tilde{q}_{i t}=q_{i o} \exp \left(\alpha_{t}-\alpha_{0}\right)$. Measuring (22) relative to total expenditure $E_{t}=\sum i p_{i t} x_{i t}=$ $u t e(q t)$, we obtain Proposition 2.

This result provides a precise measure of the deadweight loss of the auto, over and above that of the price-equivalent tariff. With the demands $x_{i t}$ in (24) chosen optimally, the paasche index will be less than the exact index for two reasons: those varieties with the greatest increase in service-prices will have falling demand, and the Paasche index uses the current-period demand $x_{i t}$ to evaluate the overall price increase; the service-prices in the denominator of (24) are constructed using the constant weights $\gamma$, which exceed the welfare weights

13 We continue to treat the markups on each variety as equal and constant, so that the error term in $(16)$ is zero. 
$\beta_{\text {it }}$ in (18). Thus, the increase in characteristics will lead to a greater rise in the constructed service-prices, and a smaller increase in the Paasche index. Note that both of these reasons reflect a type of quality-upgrading that occurred in the Japanese cars: the shift in demand towards more expensive and higherquality models can be inferred from the more rapid rise of the unit-price and unit-quality in Table 1, as compared to the price and quality indexes, respectively: whereas the increase in characteristics and fall in their welfare value has been the focus of our discussion throughout this section. 14

An interpretation of Proposition 2 can be obtained from the familiar case of taxing two commodities in the absence of any characteristics, as shown in Figure 1. We assume that the price of good 1 exceeds that of good 2 initially. with a consumption vector of $x_{0}$ and utility of $U_{0}$. Holding expenditure constant and taxing both commodities at the dollar rate s, will shift the budget line in a non-parallel manner to $A_{1} B_{1}$. with consumption at $x_{1}$ and utility of $U_{1}$. Quality upgrading is illustrated by the substitution towards the higher-priced good 1 due to this tax. In order to raise the same revenue from an af valorem tax of $\tau$, the budget line will instead become $A_{2} B_{2}$ passing through $x_{1}$, but yielding higher utility of $U_{2}$ at $x_{2}$. The deadweight loss of the dollar tax $s$ - which is analogous to the VER - compared to the ad valorem tax $\tau$ is then $U_{2}-U_{1}$.

To measure this deadweight loss relative to the initial utility $U_{0}$, suppose that utility is homogeneous of degree one in consumption. Then the ratio $U_{1} / U_{0}$ is measured by an exact quantity index between $x_{0}$ and $x_{1}$. Since expenditure is constant, $U_{1} / U_{0}$ is equivalently measured by the inverse of an exact price index between $p_{0}$ and $p_{1}$. Turning to the ratio $U_{2} / U_{0}$. it is measured by the inverse of the increase in prices (rom $p_{0}$ to $P_{2}$ on the budget lines $A_{0} B_{0}$ and $A_{2} B_{2}$, relative

\footnotetext{
14 A simplified version of Proposition 2, that applies when characteristics are
} constant and only demand shifts, is obtained by Boorstein and Feenstra (1991). 
to any fixed consumption vector. Choosing the reference vector $x_{1}$, we obtain $U_{2} / U_{0}=\left(p_{2}^{j} x_{1} / p_{0}^{\prime} x_{1}\right)^{-1}$. Since the budget lines $A_{1} B_{1}$ and $A_{2} B_{2}$ both pass through $x_{1}$. then $p_{2} x_{1}=p_{j} x_{1}$ by construction. It follows that $U_{2} / U_{0}=\left(p_{j} x_{1} / p_{j} x_{1}\right)^{-1}$, which is precisely the inverse of a Paasche price index between $p_{0}$ and $p_{1}$. Thus, the deadweight loss $\left(U_{2}-U_{1}\right) U_{0}$ is obtained as the difference between the inverse of the Paasche and exact indexes, as in Proposition 2.15

Near the bottom of Table 1 we report the quality-adjusted Paasche index, relative to a 1980 base, calculated as in (24). As expected, this index rises slower than the bounds for the exact index. The deadweight loss in (23) is computed using these indexes, and is obtained as a percent of expenditure on total imports: the range of estimates obtained using the bounds for the exact index are reported at the bottom of Table 1. It can be seen that the deadweight loss ranges from 4.5 to 6.4 percent of expenditure in 1984-85.

In the final row. the figures in parentheses give the average deadweight loss expressed as a percentage of the quality upgrading, i.e, expressed relative to the change in the unit-quality since 1980. For example, the average deadweight loss of $6.15 \%$ in 1985 is $\$ 501$ per auto. while the upgrading since 1980 is $\$ 1608$. so the deadweight loss is $31.2 \%$ of the upgrading. Estimates this high also occur in other years, and except for 1981, the deadweight loss is roughly between one-quarter and one-third of the value of the upgrading. The large magnitude of this deadweight loss reflects both the reduced value that consumers put on the additional characteristics, and the induced substitution towards higher-priced cars.

As a check on the magnitude of the deadweight loss, we also recomputed

15 The extra term exp $\left(\alpha_{t}-\alpha_{0}\right)$ multiplying the loss in (23) reflects the inflationary rise in free-trade prices over time, and would offset the corresponding rise in the paasche and exact price indexes due to inflation. 
the upper and lower bounds of the exact index using the same set of 1980 models as used for Paasche index. That is, we excluded the new models that appear in the sample. and which are incorporated into the exact indexes in Table 2 after they occur for two years.16 The resulting upper and lower bounds for the exact index are identical to those in Table 1 for 1980-83, and take on the slightly lower values of 4.2-4.9 for 1984, and 5.6-6.1 for 1985. As a result, the average deadweight loss relative to the quality upgrading is very slightly smaller at $25.0 \%$ in 1984 and $29.7 \%$ in 1985 . Thus, the appearance of the new models does not significantly affect our results.

\section{CONCLUSIONS}

In this paper we have examined the "explicit quality adjustment" used in constructing a hedonic price index, and found that this method can be justified on theoretical grounds. Our assumptions include the separability of characteristics and quantities in the underlying utility function, and it is worth emphasizing that this functional form is quite special. Spence (1975) considers more general utility functions, and is clearly interested in the welfare implications of the policies that he discusses. While it is reassuring that the nedonic quality adjustment can be given some justification, further research is needed to determine whether the separability assumption can be removed. Initial steps along these lines are contained in the exchange between Diewert (1980a,b) and Denny (1980): Diewert (1980a) discusses a broad range of index number methods applied to the aggregation of capital, including hedonic methods (pp. 503-506);

\footnotetext{
16 In the first year that a new model appears, it is excluded from any price index constructed between that year and the previous one. In the second year, the model is incorporated into the year-to-year price index, and the cumulative values of the indexes are reported in Table 1 . In contrast, the Paasche index is constructed relative to the 1980 set of models.
} 
Denny (1980) responds by questioning whether a separability assumption used by Diewert is really necessary: and Diewert (1980b) replies by suggesting several approaches that do not require this assumption.

We have applied our results to evaluate the welfare impact of the quality upgrading that occurred in U.S. imports of Japanese cars, under the "voluntary" export restraint. Under this trade restriction, consumers do not value the additional characteristics at their former shadow-values, but rather, by a reduced amount. We find that the deadweight loss of the quality upgrading is very large: between one-quarter and one-third of the value of the upgrading, or $\$ 500$ in 1985 . This deadweight loss is additional to the losses that result from transferring the quota rents to Japanese firms (about $\$ 1,00$ per car in 1984-85, from Feenstra, 1988), and also the conventional deadweight loss from reducing the total purchases of cars. Quantifying the loss due to quality upgrading illustrates the usefulness of having a welfare interpretation for hedonic price indexes, and we expect that this interpretation will be useful in other applications, as well. 


\section{REFERENCES}

Abel, Andrew B. (1983) "Market Structure and the Durability of Goods," Review of Economic Studies, 50, 625-637.

Anderson, Simon P., Andre de Palma and Jacques-francois Thisse (1992) Discrete Choice Theory of Product Differentiation. Cambridge, MA: MIT Press.

Anderson, Simon P., Andre de Palma and Jacques-Francois Thisse (1989) "Demand for Differentiated Products, Discrete Choice Models, and the Characteristics Approach," Review of Economic Studies. 21-35.

Boorstein, Randi and Robert C. Feenstra (1991) "Quality Upgrading and its Welfare Cost in U.S. Steel Imports, 1969-74, in Elhanan Helpman and Assaf Razin, eds., International Trade and Trade Policy. Cambridge. MA: MIT Press, 167-186.

Bresnahan, Timothy F. and Dennis A. Yao (1985) "The Nonpecuniary Costs of Automobile Emissions Standards." Rand Journal of Economics. 18(4). Winter. 437-455.

Denny, Michael (1980) "Comment," in Dan Usher, ed., The Measurement of Capital. Chicago: Univ. of Chicago and NBER, 528-538.

Diewert. W. Erwin (1976) "Exact and Superlative Index Numbers," Journal of Econometrics, $4,115-145$.

Diewert, W. Erwin (1978) "Superlative index Numbers and Consistency in Aggregation." Econometrica, 46(4), July. 883-900.

Diewert. W. Erwin (1980a) Aggregation Problems in the Measurement of Capital," in Dan Usher, ed., The Measurement of Capital. Chicago: Univ. of Chicago and NBER, 433-528.

Diewert. W. Erwin (1980b) "Reply." in Dan Usher, ed., The Measurement of Capital, Chicago: Univ. of Chicago and NBER, 538.

Feenstra, Robert C. (1988) "Quality Change Under Trade Restraints in Japanese Autos," Quarterly Journal of Economics. February. 131-146.

Feenstra, Robert C. and James A. Levinsohn (1991) "Oligopoly Pricing and the Characteristics Approach." University of California, Davis and University of Michigan, mimeo. 
Fisher, Franklin M. and Karl Shell (1972) The Economic Theory of Price Indices. New York: Academic Press.

Gordon, Robert J. (1990) Ihe Measurement of Durable Goods Prices. Chicago: Univ. of Chicago and NBER.

Griliches, Zvi (1990) Hedonic Price Indexes and the Measurement of Capital and Productivity." in Ernst R. Berndt and Jack E. Triplett, eds., Fifty Years of Economic Measurement, Chicago: University of Chicago and NBER, 185-202.

Jorgenson, Dale W. (1990) Aggregate Consumer Behviour and the Measurement of Social Welfare." Econometrica. 58(5), September, 1007-1040.

Krishna, Kala (1987) "Tariffs vs. Quotas with Endogenous Quality." Journal of International Economics, 23, August, 97-117.

Rodriguez, Carlos A. (1979) "The Quality of Imports and the Differential Effects of Tariffs, Quotas, and Quality Controls as Protective Devices," Canadian Journal of Economics. 12(3). August, 439-449.

Rosen, Sherwin (1974) "Hedonic Prices and Implicit Markets: Product Differentiation in Pure Competition." Journal of Political Economy, 34-55.

Spence, A. Michael (1975) "Monopoly, Quality, and Regulation." The Bell Journal of Economics, 6(2), Autumn, 417-429.

Swan, Peter L. (1970) "Durability of Consumption Goods," American Economic Review, 60(5), December, 884-894.

Triplett, Jack E. (1986) "The Economic Interpretation of Hedonic Methods," Survey of Current Business, U.S. Dept. of Commerce, January, 36-40.

Triplett, Jack E. (1987) "Hedonic Functions and Hedonic Indexes," in John Eatwell, Murray Milgate and Peter Newman, eds. The New Palgrave: A Dictionary of Economics, vol. 2, New York: McMillan Press, 630-634.

Triplett, Jack E. (1990) Hedonic Methods in Statistical Agency Environments: An Intellectual Biopsy," in Ernst R. Berndt and Jack E. Triplett, eds., Fifty Years of Economic Measurement. Chicago: University of Chicago and NBER, 207-233. 
Table 1 - Price Indexes for Sample of Japanese Cars

$\begin{array}{llllll}1980 & 1981 & 1982 & 1983 & 1984 & 1985\end{array}$

\begin{tabular}{|c|c|c|c|c|c|c|}
\hline Number of Models & 24 & 24 & 24 & 26 & 29 & 31 \\
\hline $\begin{array}{l}\text { Unit-Value }{ }^{a}(\$) \\
\text { (percent change) }\end{array}$ & $\begin{array}{r}5.175 \\
(4.6)\end{array}$ & $\begin{array}{l}6.211 \\
(20.0)\end{array}$ & $\begin{array}{l}6.834 \\
(10.0)\end{array}$ & $\begin{array}{r}7.069 \\
(3.4)\end{array}$ & $\begin{array}{r}7.518 \\
(6.4)\end{array}$ & $\begin{array}{r}8.153 \\
(8.4)\end{array}$ \\
\hline $\begin{array}{l}\text { Price Indexa } \\
\text { (percent change) }\end{array}$ & $\begin{array}{r}100.0 \\
(3.2)\end{array}$ & $\begin{array}{l}119.8 \\
(19.8)\end{array}$ & $\begin{array}{r}129.1 \\
(7.8)\end{array}$ & $\begin{array}{r}131.6 \\
(1.9)\end{array}$ & $\begin{array}{r}138.8 \\
(5.5)\end{array}$ & $\begin{array}{r}149.0 \\
(7.4)\end{array}$ \\
\hline $\begin{array}{l}\text { Unit-Quality }(\$) \\
\text { (percent change) }\end{array}$ & $\begin{array}{r}5.147 \\
(2.4)\end{array}$ & $\begin{array}{r}5.536 \\
(7.6)\end{array}$ & $\begin{array}{r}5.923 \\
(7.0)\end{array}$ & $\begin{array}{r}6,287 \\
(6.1)\end{array}$ & $\begin{array}{r}6.518 \\
(3.7)\end{array}$ & $\begin{array}{r}6.755 \\
(3.6)\end{array}$ \\
\hline $\begin{array}{l}\text { Quality Indexa } \\
\text { (percent change) }\end{array}$ & $\begin{array}{r}100.0 \\
(1.3)\end{array}$ & $\begin{array}{r}107.4 \\
(7.4)\end{array}$ & $\begin{array}{r}112.8 \\
(5.0)\end{array}$ & $\begin{array}{r}117.4 \\
(4.1)\end{array}$ & $\begin{array}{r}121.3 \\
(3.4)\end{array}$ & $\begin{array}{r}125.8 \\
(3.7)\end{array}$ \\
\hline $\begin{array}{l}\text { Price/Quality Ratiob } \\
\text { (percent change) }\end{array}$ & $\begin{array}{r}100.0 \\
(1.9)\end{array}$ & $\begin{array}{l}111.5 \\
(11.5)\end{array}$ & $\begin{array}{r}114.5 \\
(2.7)\end{array}$ & $\begin{array}{l}112.1 \\
(-2.1)\end{array}$ & $\begin{array}{r}114.4 \\
(2.1)\end{array}$ & $\begin{array}{r}118.4 \\
(3.5)\end{array}$ \\
\hline $\begin{array}{l}\text { Exact Index, Lower Bndc } \\
\text { (percent change) }\end{array}$ & $\begin{array}{r}100.0 \\
(1.5)\end{array}$ & $\begin{array}{l}112.5 \\
(12.5)\end{array}$ & $\begin{array}{r}115.9 \\
(3.0)\end{array}$ & $\begin{array}{l}113.7 \\
(-1.9)\end{array}$ & $\begin{array}{r}116.9 \\
(2.8)\end{array}$ & $\begin{array}{r}121.1 \\
(3.5)\end{array}$ \\
\hline $\begin{array}{l}\text { Exact Index, Upper Bndc } \\
\text { (percent change) }\end{array}$ & $\begin{array}{r}100.0 \\
(1.5)\end{array}$ & $\begin{array}{l}113.0 \\
(13.0)\end{array}$ & $\begin{array}{r}116.6 \\
(3.2)\end{array}$ & $\begin{array}{l}114.6 \\
(-1.7)\end{array}$ & $\begin{array}{r}117.8 \\
(2.8)\end{array}$ & $\begin{array}{r}121.7 \\
(3.3)\end{array}$ \\
\hline $\begin{array}{l}\text { Paasche Index } \\
\text { (percent change) }\end{array}$ & $\begin{array}{r}100.0 \\
(3.0)\end{array}$ & $\begin{array}{l}111.4 \\
(11.4)\end{array}$ & $\begin{array}{r}113.0 \\
(1.4)\end{array}$ & $\begin{array}{l}109.4 \\
(-3.2)\end{array}$ & $\begin{array}{r}111.1 \\
(1.6)\end{array}$ & $\begin{array}{r}114.1 \\
(2.7)\end{array}$ \\
\hline $\begin{array}{l}\text { Deadweight } \text { Loss }^{d}(x) \\
\text { (percent of upgrading)e }\end{array}$ & - & $\begin{array}{c}0.9-1.3 \\
(17.6)\end{array}$ & $\begin{array}{c}3.7-4.2 \\
(34.8)\end{array}$ & $\begin{array}{c}3.3-4.0 \\
(22.6)\end{array}$ & $\begin{array}{r}4.5-5.1 \\
(26.3)\end{array}$ & $\begin{array}{c}5.9-6.4 \\
(31.2)\end{array}$ \\
\hline
\end{tabular}

\section{Notes}

a Revised from Feenstra (1988).

b Equals the price index divided by the quality index, multiplied by 100 .

c Calculated as in Proposition 1.

d Calculated as in Proposition 2.

e Equals the average of the range in the row just above, multiplied by the unitvalue for that year, divided by the increase in the unit-quality since 1980 . 
Figure 1

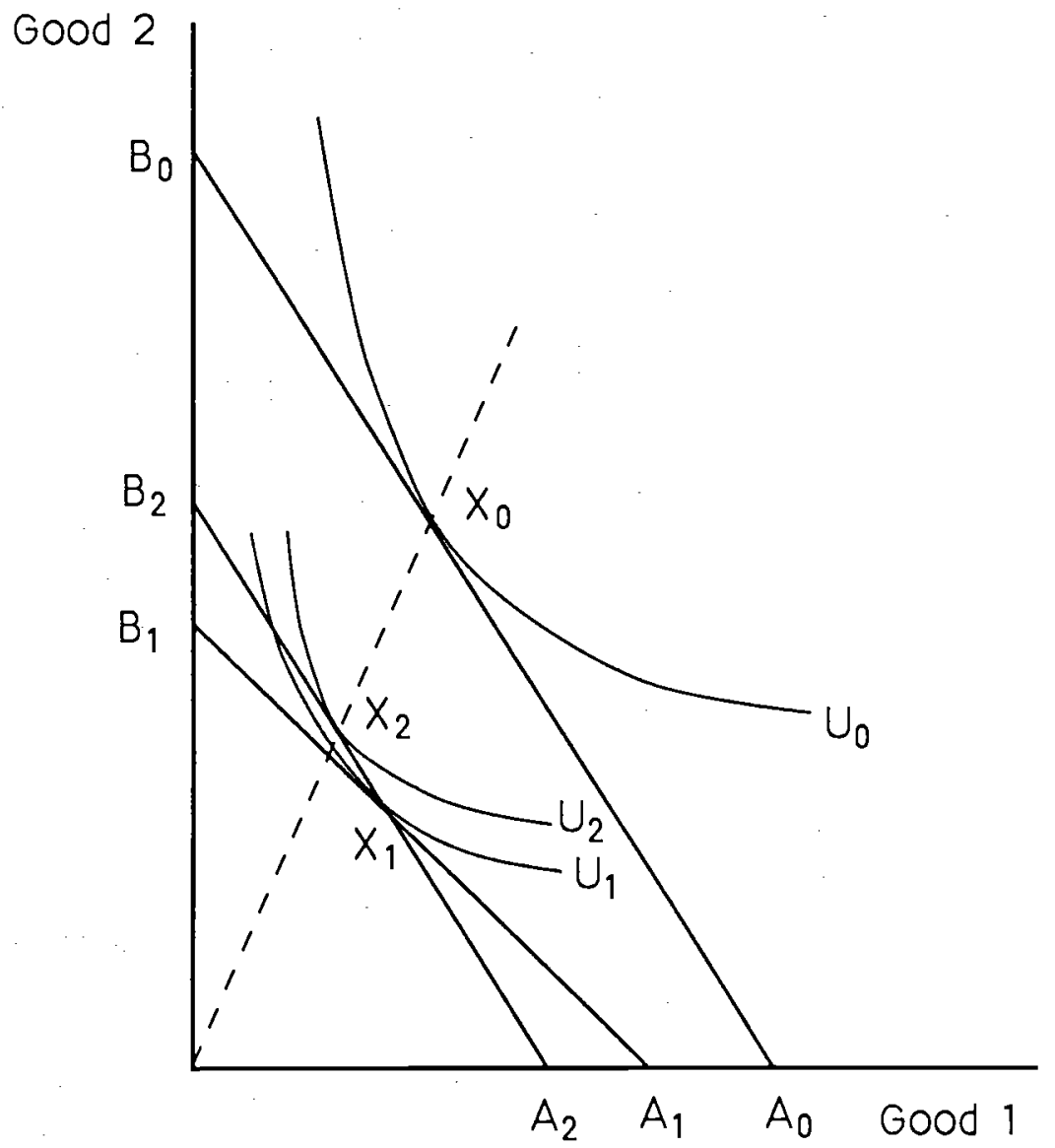




\section{APPENDIX}

The first column of Table 1 reports the estimated regression (16) from Feenstra (1988). It is difficult to separately estimate the parameters $\alpha_{t}$ and the quota premiums $s_{t}$. since they are both parameters of year dummies. This problem was resolved in Feenstra (1988) by pooling the Japanese auto data for (17) with Japanese truck data. where the U.S. imports of Japanese trucks are subject to a tariff but not the quota. In this pooling, the cars and trucks are treated as having different vectors of characteristics, and there is no quota premium on trucks. In addition, a relation between the parameters $\alpha_{t}$ for cars and trucks, stating that these annual changes in prices are identical after correcting for the ad valorem tariff in trucks and the VER in cars, was tested and accepted for 1980-84. This constraint is imposed in the estimates reported.

In column two we report estimates of (16) for 1985 only. utilizing the estimates of the markups $\hat{\mu}_{i 85}$ from Feenstra and Levinsonn (1991). In that year. the quota premium $s_{g 5}$ is insignificantly different than zero in column one. and is set equal to zero. Assuming a log-linear form for the marginal costs, we estimate the following relations:

$$
\begin{aligned}
\ln \left[\left(1-\hat{\mu}_{i B 5}\right)_{P_{i 85}}\right) & =\alpha_{85}+\gamma \cdot z_{185}+\varepsilon_{i 85} . \\
\ln \left(p_{i 85}\right) & =\alpha_{85}+\gamma \cdot z_{i 85}+\varepsilon_{i 85} .
\end{aligned}
$$

where the markups $\hat{\mu}_{185}$ are incorporated into the first relation, but not the second. The estimates for ( $A 1$ ) are reported in column two, and that for (A2) in column three. It is apparent that the change in the coefficients $\delta$ due to the change in the dependent variable is not large. as compared to their standard errors. Thus, the potential bias due to using price rather than marginal revenue as the dependent variable in (16) is not important in these estimates. 


\section{Iable Al - Hedonic Regressions}

\begin{tabular}{|c|c|c|c|c|}
\hline Dependent Variable & & & Marginal Revenue & Price \\
\hline Years, Obs. & 197 & 179 & 1985,25 & 1985,25 \\
\hline$R^{2}$ & & & 0.92 & 0.95 \\
\hline Weight (tons) & & $\begin{array}{l}0 \\
08)\end{array}$ & $\begin{array}{c}0.52 \\
(0.46)\end{array}$ & $\begin{array}{c}0.23 \\
(0.36)\end{array}$ \\
\hline Width (feet) & & & $\begin{array}{l}0.80 \\
(0.32)\end{array}$ & $\begin{array}{l}0.66 \\
(0.25)\end{array}$ \\
\hline Height (leet) & & & $\begin{array}{l}-0.26 \\
(0.19)\end{array}$ & $\begin{array}{l}-0.21 \\
(0.15)\end{array}$ \\
\hline Horsepower $(100)$ & & 72) & $\begin{array}{c}0.22 \\
(0.25)\end{array}$ & $\begin{array}{c}0.40 \\
(0.19)\end{array}$ \\
\hline $\begin{array}{l}\text { Transmission } \\
\text { (5-speed or auto })\end{array}$ & & 86) & $\begin{array}{c}0.15 \\
(0.069)\end{array}$ & $\begin{array}{c}0.19 \\
(0.021)\end{array}$ \\
\hline Power steering & & & $\begin{array}{c}0.062 \\
(0.071)\end{array}$ & $\begin{array}{c}0.089 \\
(0.055)\end{array}$ \\
\hline Air Conditioning & & & $\begin{array}{l}0.15 \\
(0.12)\end{array}$ & $\begin{array}{c}0.13 \\
(0.091)\end{array}$ \\
\hline Year 1980 & $\begin{array}{c}\frac{\alpha_{t}}{0.011} \\
(0.025)\end{array}$ & $s_{t}$ & & \\
\hline Year 1981 & $\begin{array}{c}0.049 \\
(0.040)\end{array}$ & $\begin{array}{c}434 \\
(250)\end{array}$ & - & - \\
\hline Year 1982 & $\begin{array}{c}0.045 \\
(0.041)\end{array}$ & $\begin{array}{l}707^{*} \\
(256)\end{array}$ & - & - \\
\hline Year 1983 & $\begin{array}{l}-0.024 \\
(0.044)\end{array}$ & $\begin{array}{l}1085^{*} \\
(262)\end{array}$ & - & - \\
\hline Year 1984 & $\begin{array}{c}0.016 \\
(0.044)\end{array}$ & $\begin{array}{l}1096^{*} \\
(267)\end{array}$ & - & - \\
\hline Year 1985 & $\begin{array}{l}0.169^{\prime \prime} \\
(0.069)\end{array}$ & $\begin{array}{l}256 \\
(492)\end{array}$ & - & - \\
\hline
\end{tabular}

\section{Notes}

- Significant at the 95\% level. Standard errors are in parentheses. Estimates in column one are from Feenstra (1988). 